\title{
O SILENCIAMENTO DO MULTICULTURALISMO NA PAUTA DAS UNIVERSIDADES FEDERAIS DO SUDESTE E NORDESTE BRASILEIRO: TENDÊNCIAS NA FORMAÇÃO DO BIBLIOTECÁRIO E CIENTISTA DA INFORMAÇÃ̃O
}

THE SILENCING OF MULTICULTURALISM IN THE AGENDA OF THE FEDERAL UNIVERSITIES OF SOUTHEAST AND NORTHEAST BRAZIL: TRENDS IN THE FORMATION OF LIBRARIAN AND INFORMATION SCIENCE SCIENTIST

EL SILENCIAMIENTO DEL MULTICULTURALISMO EN LA PAUTA DE LAS UNIVERSIDADES PÚBLICAS DEL SURESTE Y NORDESTE BRASILERO: TENDENCIAS EN LA FORMACIÓN DEL BIBLIOTECARIO Y CIENTISTA DE LA INFORMACIÓN

${ }^{1}$ Claudio Moises da Costa

'Patricia Vargas Alencar

Universidade Federal do Estado do Rio de Janeiro ${ }^{1}$

\section{Correspondência}

1Patricia Vargas Alencar

Universidade Federal do Estado do Rio de Janeiro

Rio de Janeiro, RJ - Brasil.

Email: pat.vargas@hotmail.com

ORCID: http://orcid.org/0000-0003-3670-0909

Submetido em: $23 / 07 / 2017$

Aceito em: 30/01/2018

Publicado em: 19/02/2018

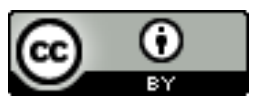

JITA: AC. Relationship of LIS with other fields. 
RESUMO: Este artigo investiga a formação do bibliotecário e do cientista da informação nas universidades federais das regiões Sudeste e Nordeste do Brasil. Mais precisamente, nossa pesquisa visa discutir até que ponto os cursos de Biblioteconomia e Ciência da Informação contemplam o Multiculturalismo no âmbito do ensino, da pesquisa e da extensão universitária. Levamos em consideração o referencial teórico do Multiculturalismo e da Educação Intercultural, realizando uma investigação de natureza qualitativa e quantitativa. As evidências apontam que as discussões sobre Multiculturalismo ainda ocorrem de forma incipiente em quatro das seis universidades do Sudeste. Mais que isso, estão ausentes em duas universidades dessa região. Por outro lado, na região Nordeste se dão de forma incipiente em quatro das oito universidades pesquisadas, estando ausente nas demais. Nosso trabalho poderá contribuir no sentido de estimular a reflexão sobre o papel da universidade face às demandas informacionais das sociedades multiculturais.

PAlaVRaS-ChaVE: Formação. Bibliotecário. Cientista da informação. Multiculturalismo. Universidades federais.

ABSTRACT: This article investigates the graduation system of librarians and information science scientists, at federal universities of the southeast and northeast regions of Brazil. More precisely, our research aims to discuss the extent to which the courses on Library Science and Information Science encompass Multiculturalism in the field of university teaching, research and extension. We take account of the theoretical framework of Multiculturalism and Intercultural Education, leading an investigation of qualitative and quantitative nature. The evidence indicates that the discussions on Multiculturalism still occurs in an incipient way in four of the six universities of the southeast. More than that, the debate is absent at two universities in this region. On the other hand, in the Northeast region it is incipient in four of the eight universities surveyed, being absent in the others. Our work may contribute to stimulate reflections on the role of the university in the informational demands of multicultural societies.

KEYWORDS: Graduation system. Librarian. Information science scientist. Multiculturalism. Federal universities.

RESUMEN: El presente artículo investiga la formación del bibliotecario y del cientista de la Información en las universidades públicas de las regiones Sureste y Nordeste de Brasil. Específicamente, nuestra investigación, apunta a discutir hasta que punto los cursos de Biblioteconomia y Ciencia de la Información contemplan el Multiculturalismo en el ámbito de la enseñanza, investigación y extensión universitaria. Consideramos como referencial teórico estudios sobre el Multiculturalismo y la Educación Intercultural, realizando una investigación de carácter cualitativo y cuantitativo. Las muestras señalan que las discusiones sobre Multiculturalismo aún ocurren de forma incipiente en cuatro de las seis universidades del Sureste. Y están ausentes en dos universidades de esa región. Por otro lado, en la región Nordeste las discusiones acontecen tímidamente en cuatro de las ocho universidades investigadas, ausentándose la discusión en las demás. Así, nuestro trabajo podrá contribuir estimulando la reflexión sobre el papel de la universidad de cara a las demandas informacionales de las sociedades multiculturales.

PAlabRaS ClAvE: Formación. Bibliotecario. Cientista de la Información. Multiculturalismo. Universidades públicas. 


\section{INTRODUÇÃO}

Os estudos multiculturais têm se revelado como campo teórico fértil para as pesquisas nas áreas da Biblioteconomia e da Ciência da Informação. Embora as pesquisas apontem para a urgência em se oferecer uma formação que sensibilize o profissional da informação frente às demandas informacionais da sociedade multicultural, é notório o "silenciamento" das instituições de ensino superior quanto ao tema e suas variantes (ALENCAR, 2014). Neste sentido, a questão que norteia esta pesquisa é: em que medida as universidades federais, das regiões do Nordeste e do Sudeste, oferecem disciplinas, em seus cursos de formação inicial e continuada, e ações de extensão universitária que dão a oportunidade ao profissional da informação de discutir o multiculturalismo e seus reflexos no fazer do bibliotecário e do cientista da Informação?

Fruto de nosso interesse no aprofundamento da pesquisa desenvolvida ao longo da realização das etapas do subprojeto de Iniciação Científica ${ }^{1}$, nossa pesquisa é de caráter qualitativo e quantitativo (RICHARDSON, 1999; DUARTE, 2009) e de natureza exploratória (GIL, 1999). Insere-se no quadro teórico dos estudos multiculturais (HALL, 2003; SANTOS, 2003, FLEURI, 2000) e une-se às pesquisas da revisão da literatura no tocante às discussões do Multiculturalismo nas áreas de Biblioteconomia e de Ciência da Informação.

Este trabalho tem como objeto de estudo a incidência de estudos multiculturais oferecidos nos cursos de formação do profissional da informação e tem por objetivo geral investigar até que ponto o Multiculturalismo faz parte das pautas dos cursos de Biblioteconomia e de Ciência da Informação das Universidades Federais do Nordeste e do Sudeste brasileiro no âmbito do ensino, da pesquisa e da extensão.

Para a realização de nossa pesquisa, perseguimos os seguintes objetivos específicos:

a) analisar os cursos de formação inicial (Graduação) e continuada (Pós-Graduação) para saber se temas voltados para o Multiculturalismo, Diversidade Cultural, Educação Intercultural e variantes contemplam os estudos multiculturais;

b) estudar programas e projetos de extensão universitária com vistas a verificar se a universidade se (pre)ocupa (com) de ações extensionistas interculturais;

c) discutir se as Universidades Federais do Nordeste e Sudeste apresentam um quadro de formação do profissional bibliotecário e cientista da informação favorável ao estudo do Multiculturalismo.

Este trabalho se justifica na medida em que traz contribuições para profissionais de biblioteconomia e da ciência da informação no que diz respeito às discussões sobre uma

\footnotetext{
1 Subprojeto intitulado "Formação e atuação do bibliotecário: estratégias de trabalho rumo à educação intercultural", vinculado ao projeto de Pesquisa "Dimensões da perspectiva intercultural em Bibliotecas: tendências em informação, educação e trabalho", coordenado pela professora Patrícia Vargas Alencar, docente do Programa de Mestrado Profissional em Biblioteconomia da Universidade Federal do Estado do Rio de Janeiro (UNIRIO).
}

V.16

n.2

p.433-460

maio/ago. 2018 
questões cruciais do multiculturalismo.

Multiculturalismo é um termo hoje utilizado universalmente, o que não contribui para estabilizar ou esclarecer o seu significado. Ele é utilizado em várias áreas do conhecimento, e encontra-se frequentemente em meio aos discursos políticos. Muito por isso, assim como outros termos relacionados - "raça", etnicidade, identidade, diáspora - o "multiculturalismo" se encontra tão discursivamente enredado que só pode ser utilizado "sob rasura"4. (HALL, 2003, p. 51)

Para Hall, é importante fazer uma distinção entre o termo Multicultural e o termo Multiculturalismo.

\begin{abstract}
Multicultural é um termo qualificativo. Descreve as características sociais e os problemas de governabilidade apresentados por qualquer sociedade na qual diferentes comunidades culturais convivem e tentam construir uma vida em comum, ao mesmo tempo em que retêm algo de sua identidade "original". Em contrapartida, o termo Multiculturalismo é substantivo. Refere-se às estratégias adotadas para governar ou administrar problemas de diversidade e multiplicidade gerados pelas sociedades multiculturais. Significa, usualmente, a filosofia específica ou a doutrina que sustenta as estratégias multiculturais. (HALL, 2003, p. 52)
\end{abstract}

No conceito de multiculturalismo trabalhado por Hall (2003), percebe-se que as noções dos "Estudos Culturais" estão frequentemente presentes. O autor propõe, no estudo do multiculturalismo, a relevância da ideia de cultura, considerando condições específicas e históricas de cada tempo. As abordagens dos "Estudos Culturais" por Hall refletem na função teórica e política, fundando diferentes campos, fundamentando desta forma também o conceito do multiculturalismo.

Segundo Santos e Nunes (2003), multiculturalismo, justiça multicultural, sociedade multicultural e direitos coletivos são algumas das expressões utilizadas para definir as tensões entre o reconhecimento da diferença e a realização da igualdade, que estão no centro de lutas, de movimentos e grupos que buscam um ideal de cidadania e a defesa pelas discussões do multiculturalismo.

A Federação Internacional de Associações de Bibliotecários e Instituições (IFLA) é o principal órgão internacional que representa os interesses dos serviços de bibliotecas, de informação e de seus usuários. Trata-se de uma organização independente, nãogovernamental e sem fins lucrativos. É a voz global da biblioteca e dos profissionais bibliotecários. A IFLA, através de seus manifestos e diretrizes, tem como objetivo promover padrões elevados de prestação de serviços de biblioteca e informação, incentivar a compreensão generalizada do valor dos bons serviços de biblioteca e informação e representar os interesses dos membros em todo o mundo. No manifesto "Por La Biblioteca Multicultural", a IFLA, em parceria com a UNESCO, divulga que:

\footnotetext{
${ }^{4}$ HALL, Stuart. "A questão multicultural”. Op. Cit. p. 51. Essa expressão se refere às dificuldades de utilizar termos e conceitos extremamente complexos e amplamente discutidos, que impossibilitam abordagens mais precisas das realidades que tentam compreender.
}

n.2

p.433-460 maio/ago. 2018 


\begin{abstract}
A "Diversidade Cultural" ou "Multiculturalismo" refere-se à coexistência harmoniosa e à interação de diferentes culturas, onde "a cultura deve ser considerada como o conjunto de características espirituais, materiais, intelectuais e emocionais distintivas da sociedade ou de um grupo social e que engloba, além de arte e literatura; estilos de vida, formas de convivência, sistemas de valores, tradições e crenças" ${ }^{5}$. A diversidade cultural ou multiculturalismo é a base de nossa força coletiva em nossas comunidades locais e em nossa sociedade global. (IFLA, 2008, p.1)
\end{abstract}

Para Fleuri (2000), o debate no Brasil sobre as relações multiculturais e interculturais na educação é bem recente. A discussão é estimulada por estudos originados na Europa e América do Norte. Trata-se de um debate complexo em que participam diferentes concepções teóricas e políticas. $\mathrm{O}$ autor destaca que a educação intercultural ultrapassa a perspectiva multicultural:

\begin{abstract}
Esta reconhece o valor intrínseco de cada cultura e defende o respeito recíproco entre diferentes grupos identitários. Além disso, educação intercultural propõe construir a relação recíproca entre eles. Uma relação que se dá, não abstratamente, mas entre pessoas concretas. Entre sujeitos que decidem construir contextos e processos de aproximação, de conhecimento recíproco e de interação. Relações estas que produzem mudanças em cada indivíduo, favorecendo a consciência de si e reforçando a própria identidade. (FLEURI, 2000, p. 79)
\end{abstract}

Levando em conta todos os desafios que os bibliotecários e cientistas da Informação encontram na sua atuação profissional, seja em um ambiente educativo ou não, é esperado que esses profissionais estejam sensibilizados para atender às demandas de uma sociedade culturalmente diversa, e por esse motivo é desejável que a temática do multiculturalismo e a educação intercultural estejam presentes de forma significativa desde a sua formação inicial, até a sua formação continuada com vistas a uma atuação proativa e acolhedora.

Considerando as dificuldades para a definição precisa do termo, pode-se afirmar que multiculturalismo se tornou um modo de destacar as diferenças culturais em um contexto global. Pode ser associado a projetos e a conteúdos de emancipação e contra a hegemonia cultural, amparados nas lutas pelo reconhecimento das diferenças. Nessa oportunidade adotamos o termo Multiculturalismo na sua concepção original segundo Boaventura Santos (2003), para quem a expressão Multiculturalismo designa "a coexistência de formas culturais ou de grupos caracterizados por culturas diferentes no seio de sociedades "modernas"". (SANTOS, 2003, p. 26).

\title{
2.2 Procedimentos Metodológicos
}

Nesta seção, apresentamos os procedimentos metodológicos adotados em nossa pesquisa, bem como fazemos o seu enquadramento de acordo com a sua natureza. Trata-se de uma pesquisa que pode ser considerada como qualitativa e como quantitativa na medida em que, segundo Duarte (2009):

${ }^{5}$ Declaração Universal da UNESCO sobre a diversidade cultural em 2001.

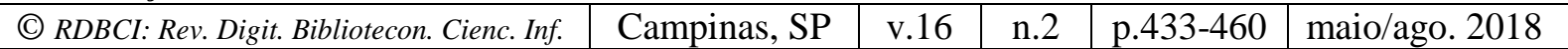


Os métodos qualitativos e os quantitativos podem combinar-se de diferentes formas numa mesma investigação. Apesar de existir uma preponderância do quantitativo sobre o qualitativo, sendo a investigação qualitativa facilitadora da quantitativa, a investigação quantitativa também pode ser facilitadora da qualitativa, ou, ainda, ambas assumirem a mesma importância. (DUARTE, 2009, p.15)

Para classificar a nossa pesquisa com base nos objetivos, recorremos aos conceitos de pesquisas exploratórias, descritos por Gil (2002).

Estas pesquisas têm como objetivo proporcionar maior familiaridade com o problema, com vistas a torná-lo mais explícito ou a constituir hipóteses. Pode-se dizer que estas pesquisas têm como objetivo principal o aprimoramento de ideias ou a descoberta de intuições. (GIL, 2002, p.41)

Para classificar a nossa pesquisa com base nos procedimentos técnicos utilizados, nos baseamos nos conceitos da pesquisa documental, também descritos por Gil (2002).

O desenvolvimento da pesquisa documental segue os mesmos passos da pesquisa
bibliográfica. Apenas cabe considerar que, enquanto na pesquisa bibliográfica as
fontes são constituídas sobretudo por material impresso localizado nas bibliotecas,
na pesquisa documental, as fontes são muito mais diversificadas e dispersas. Há, de
um lado, os documentos "de primeira mão", que não receberam nenhum tratamento
analítico. Nesta categoria estão os documentos conservados em arquivos de órgãos
públicos e instituições privadas, tais como associações científicas, igrejas,
sindicatos, partidos políticos etc. Incluem-se aqui inúmeros outros documentos
como cartas pessoais, diários, fotografias, gravações, memorandos, regulamentos,
ofícios, boletins etc. (GIL, 2002, p.46)

Considerando os conceitos anteriormente mencionados por Gil (2002), optamos, de acordo com o nosso objetivo, pela pesquisa exploratória utilizando como procedimento técnico a pesquisa documental. Primeiramente levantando os dados qualitativos obtidos através do acesso aos sites das instituições e consultas por e-mail, e posteriormente confrontando-os com os dados quantitativos coletados, em sua maioria, por intermédio de acesso aos sites das instituições de modo a torná-los mais robustos.

Inicialmente consideramos somente o curso de Biblioteconomia na matriz curricular das universidades federais do Estado do Rio de Janeiro. Ao estender a pesquisa para a Região Sudeste, notamos que na Universidade Federal de São Carlos (UFSCAR), o curso de graduação era denominado Biblioteconomia e Ciência da Informação, formando profissionais bacharéis em Biblioteconomia.

Ao selecionar quais instituições federais oferecem o curso de graduação em Biblioteconomia, nos deparamos com dados no site ${ }^{6}$ do Conselho Regional de Biblioteconomia da $6^{\mathrm{a}}$ Região (CRB - 6), fornecidos pelo Instituto Nacional de Estudos e Pesquisas Educacionais Anísio Teixeira (INEP), que demonstram que a maior concentração dessas instituições federais está na Região Sudeste e na Região Nordeste. Consultamos

${ }^{6}$ Site do CRB - 6, http://www.crb6.org.br/carreira.php, acesso em 20/07/2014

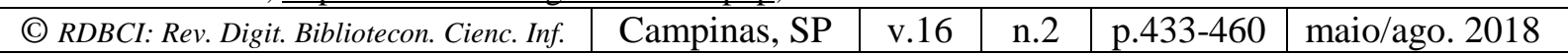




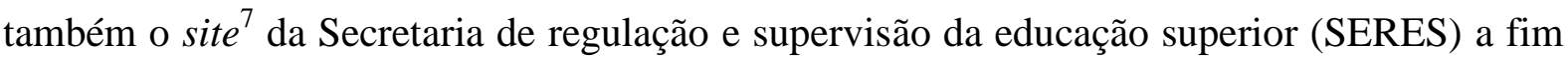
de verificar quais instituições das duas regiões ofertam os cursos de formação pesquisados. Portanto, diante desta informação, elegemos as duas regiões como cenário para nossa pesquisa.

Nosso recorte para as regiões Sudeste e Nordeste abrange as instituições federais de ensino superior que oferecem o curso de Biblioteconomia no ensino (Graduação), como também, o curso de Ciência da Informação ou Biblioteconomia na Pesquisa (Pós-graduação), conforme os Quadros 1 e 2 apresentados abaixo, respectivamente por região:

Quadro 1. Universidades Federais da Região Sudeste e seus respectivos cursos ofertados.

\begin{tabular}{|c|c|c|}
\hline Universidades & Ensino (Graduação) & Pesquisa (Pós-graduaçãa) \\
\hline UFRJ & $\begin{array}{l}\text { Biblioteconomia } \\
\text { (Bacharelado) }\end{array}$ & $\begin{array}{c}\text { Ciência da Informação (Mestrado } \\
\text { e Doutorado) }\end{array}$ \\
\hline UFF & $\begin{array}{l}\text { Biblioteconomia } \\
\text { (Bacharelado) }\end{array}$ & $\begin{array}{c}\text { Ciência da Informação (Mestrado } \\
\text { e Doutorado) }\end{array}$ \\
\hline UNIRIO & $\begin{array}{c}\text { Biblioteconomia } \\
\text { (Bacharelado e Licenciatura) }\end{array}$ & $\begin{array}{c}\text { Biblioteconomia } \\
\text { (Mestrado Profissional) }\end{array}$ \\
\hline UFSCAR & $\begin{array}{l}\text { Biblioteconomia e Ciência da Informação } \\
\text { (Bacharelado) }\end{array}$ & $\begin{array}{l}\text { Ciência da Informação } \\
\text { (Mestrado) }\end{array}$ \\
\hline UFES & $\begin{array}{l}\text { Biblioteconomia } \\
\text { (Bacharelado) }\end{array}$ & Não ofertado \\
\hline UFMG & $\begin{array}{l}\text { Biblioteconomia } \\
\text { (Bacharelado) }\end{array}$ & $\begin{array}{c}\text { Ciência da Informação (Mestrado } \\
\text { e Doutorado) }\end{array}$ \\
\hline
\end{tabular}

Fonte: Dados obtidos através da análise dos documentos fornecidos por cada instituição.

A seguir no Quadro 2, apresentamos as Universidades Federais da Região Nordeste e seus respectivos cursos ofertados.

Quadro 2. Universidades Federais da Região Nordeste e seus respectivos cursos ofertados.

\begin{tabular}{|c|c|c|}
\hline Universidades & Ensino (Graduação) & Pesquisa (Pós-graduação) \\
\hline UFAL & $\begin{array}{c}\text { Biblioteconomia } \\
\text { (Bacharelado) }\end{array}$ & Não ofertado
\end{tabular}

\footnotetext{
${ }^{7}$ Site da SERES, http://portal.mec.gov.br/secretaria-de-regulacao-e-supervisao-da-educacao-superiorseres/apresentacao, acesso em 10/12/2016 


\begin{tabular}{|c|c|c|}
\hline UFBA & $\begin{array}{l}\text { Biblioteconomia } \\
\text { (Bacharelado) }\end{array}$ & $\begin{array}{c}\text { Ciência da Informação (Mestrado e } \\
\text { Doutorado) }\end{array}$ \\
\hline UFC & $\begin{array}{l}\text { Biblioteconomia } \\
\text { (Bacharelado) }\end{array}$ & Ciência da Informação (Mestrado) \\
\hline UFCA & $\begin{array}{l}\text { Biblioteconomia } \\
\text { (Bacharelado) }\end{array}$ & $\begin{array}{c}\text { Biblioteconomia } \\
\text { (Mestrado Profissional) }\end{array}$ \\
\hline UFMA & $\begin{array}{l}\text { Biblioteconomia } \\
\text { (Bacharelado) }\end{array}$ & Não ofertado \\
\hline UFPB & $\begin{array}{l}\text { Biblioteconomia } \\
\text { (Bacharelado) }\end{array}$ & $\begin{array}{c}\text { Ciência da Informação (Mestrado e } \\
\text { Doutorado) }\end{array}$ \\
\hline UFPE & $\begin{array}{c}\text { Biblioteconomia } \\
\text { (Bacharelado) }\end{array}$ & Ciência da Informação (Mestrado) \\
\hline UFRN & $\begin{array}{l}\text { Biblioteconomia } \\
\text { (Bacharelado) }\end{array}$ & $\begin{array}{l}\text { Ciência da Informação } \\
\text { (Mestrado Profissional) }\end{array}$ \\
\hline
\end{tabular}

Fonte: Dados obtidos através da análise dos documentos fornecidos por cada instituição.

A coleta de dados ocorreu, em sua grande parte, por meio do acesso aos sites das instituições federais supracitadas, buscando primeiramente as informações referentes ao curso de graduação em Biblioteconomia, investigando prioritariamente documentos como: 0 Projeto Pedagógico do Curso (PPC), matriz curricular e ementas das disciplinas obrigatórias e optativas ofertadas em cada curso. Nesta fase da coleta dos dados, também foi investigado se a matriz curricular sofreu reformulações a partir do currículo original.

Utilizamos na nossa investigação os seguintes descritores: "Multiculturalismo, Diversidade Cultural, Pluriculturalismo e Sociedade Multicultural”. Durante o período inicial do processo de coleta, entre 2013 e 2015, nos deparamos como alguns sites de instituições que se encontravam em manutenção ou reformulação, fato que, por algumas vezes, dificultou bastante o acesso às informações. Em alguns casos, após diversas tentativas sem sucesso, tivemos que solicitar o acesso às informações por telefone e $e$-mail.

Nos cursos de pós-graduação (Mestrado e Doutorado), foram investigadas as matrizes curriculares e as ementas de disciplinas obrigatórias e optativas ofertadas. Para esses casos, não foi encontrado com muita frequência o Projeto Pedagógico do Curso. Enfatizamos que houve o interesse inicial na investigação dos Projetos de Iniciação Científica, porém em grande parte das instituições pesquisadas, esses dados não estavam disponíveis nos sites e nem disponíveis para divulgação externa. Diante do fato, esses dados não foram quantificados em nossa pesquisa.

Por último, foram investigadas as ações extensionistas (Programas, projetos, cursos e eventos) dentro das áreas de Biblioteconomia, Ciência da Informação, Cultura e Educação 
que contemplassem o tema investigado. Como alguns dados tinham sido coletados no período entre 2013 e 2015, houve a necessidade de uma nova investigação seguindo os mesmos critérios em 2016 para a atualização dos dados.

Após análise de todos os documentos investigados, foram gerados tabelas e gráficos, considerando o percentual da temática do Multiculturalismo encontrado no Ensino, Pesquisa e Extensão em cada instituição, conforme discutimos na seção a seguir.

\section{ANÁLISE DOS RESULTADOS}

Nesta seção, apresentamos os dados coletados e os resultados da nossa pesquisa, após a análise dos documentos fornecidos por cada instituição investigada. Ilustramos por meio das tabelas 1 e 2 os percentuais encontrados para a temática no Ensino, Pesquisa e Extensão, nas universidades da região Sudeste e Nordeste, respectivamente. Através de gráficos, ilustramos individualmente a distribuição dos percentuais incidentes para a temática no Ensino, Pesquisa e Extensão para cada instituição investigada que apresentou dado significativo. Por fim, comparamos os nossos resultados aos de outras pesquisas realizadas com o foco na formação e atuação do profissional da informação.

A tabela, a seguir, apresenta os dados obtidos para o Ensino, a Pesquisa e a extensão, no tocante ao multiculturalismo nas Instituições Federais de Ensino Superior (IFES) da Região Sudeste.

Tabela 1. Percentual da temática do Multiculturalismo conforme o Ensino, a Pesquisa e a Extensão em cada IFES (Região Sudeste).

\begin{tabular}{|c|c|c|c|c|c|c|c|}
\hline \multirow[t]{2}{*}{ Universidades } & \multicolumn{2}{|c|}{ (Graduação) } & \multicolumn{3}{|c|}{ (Pós-Graduação) } & 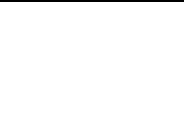 & $\begin{array}{l}\text { Extensão } \\
\text { (Ações) }\end{array}$ \\
\hline & \multicolumn{2}{|c|}{ Freq. Abs. Freq. Rel.(\%) } & \multicolumn{3}{|c|}{ Freq. Abs. Freq. Rel.(\%) } & \multicolumn{2}{|c|}{ Freq. Abs. Freq. Rel.(\%) } \\
\hline (C) RDBCI: Rev. Digi & liotecon. Cienc. Inf. & Camp & las, SP & $\mathrm{v} .16$ & n. 2 & p.433-460 & maio/ago. 2018 \\
\hline
\end{tabular}




\begin{tabular}{ccccccc}
\hline UFRJ & $0 / 96$ & 0 & $0 / 66$ & 0 & $0 / 25$ & 0 \\
UFF & $2 / 75$ & 2,66 & $0 / 25$ & 0 & $0 / 27$ & 0 \\
UNIRIO & $2 / 131$ & 1,53 & $1 / 21$ & 4,76 & $1 / 7$ & 14,28 \\
UFSCAR & $0 / 55$ & 0 & $0 / 14$ & 0 & $0 / 19$ & 0 \\
UFES & $1 / 62$ & 1,61 & $0 / 0$ & 0 & $0 / 4$ & 0 \\
UFMG & $1 / 102$ & 0,98 & $0 / 16$ & 0 & $0 / 13$ & 0 \\
\hline
\end{tabular}

Fonte: Dados obtidos através da análise dos documentos fornecidos por cada instituição.

De acordo com a Tabela 1, o tema ainda não faz parte do cenário acadêmico-cultural da Universidade Federal do Rio de Janeiro - UFRJ e nem da Universidade Federal de São Carlos - UFSCAR. Na Universidade Federal Fluminense - UFF (2,66\%), Universidade Federal do Espirito Santo - UFES $(1,61 \%)$ e Universidade Federal de Minas Gerais - UFMG $(0,98 \%)$, embora o volume de ações extensionistas seja expressivo no campo da cultura, não há programas e projetos na área de Biblioteconomia, apenas na graduação, aparecem muito discretamente disciplinas envolvidas com a proposta investigada. Por outro lado, na Universidade Federal do Estado do Rio de Janeiro (UNIRIO), conforme apontam os dados, o tema é encontrado tanto no Ensino (1,53\%), na Pesquisa (4,76\%), como na Extensão $(14,28 \%)$. Nas demais, não ocorrem dados para a pesquisa e extensão.

Os gráficos abaixo ilustram a maneira pela qual as instituições investigadas fazem a distribuição do tema multiculturalismo no ensino, pesquisa e extensão. O gráfico 1, por exemplo, apresenta os dados relacionados à Universidade Federal Fluminense (UFF):

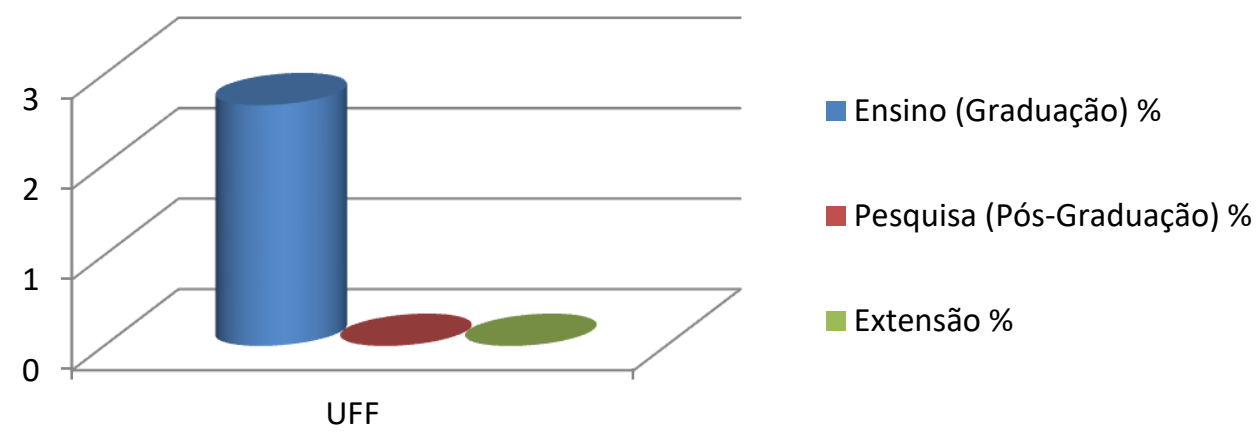

Gráfico 1. O Multiculturalismo no Ensino, Pesquisa e Extensão na Universidade Federal Fluminense (UFF)

Fonte: Dados obtidos através da análise dos documentos fornecidos pela instituição

\section{Universidade Federal Fluminense (UFF)}


${ }^{8}$ Graduação - 75 disciplinas ofertadas: 39 obrigatórias, 36 optativas

1) Ação cultural em unidades de informação (disciplina obrigatória)

2) Antropologia Cultural I (disciplina optativa)

${ }^{9}$ Pós-graduação (Mestrado e Doutorado) - 25 disciplinas ofertadas: 4 obrigatórias, 21 optativas

${ }^{10}$ Extensão - 27 Programas e projetos associados à área de cultura

No Gráfico 1, verificamos a incidência no Ensino (2,66\%) referente ao total de disciplinas ofertadas no curso de graduação, que contemplam o tema investigado. Para a Pesquisa e Extensão, não foi encontrado nenhum percentual. De acordo com o Projeto Pedagógico do Curso de Bacharelado em Biblioteconomia da UFF, são ofertadas 75 disciplinas, sendo 39 obrigatórias e 36 optativas. Analisadas as ementas de cada disciplina, concluiu-se que apenas 2 disciplinas contemplam o tema investigado, são elas: Ação Cultural em Unidades de Informação (disciplina obrigatória) e Antropologia Cultural I (disciplina optativa), correspondendo a 2,66 \% do total das disciplinas ofertadas no curso. Na pósgraduação de mestrado e doutorado em Ciência da Informação, são ofertadas 25 disciplinas, sendo 4 obrigatórias e 21 optativas, analisadas as suas ementas, concluiu-se que nenhuma contempla o tema investigado. Analisando os programas, projetos e cursos de extensão associados à área de cultura, foram encontradas 27 ações, nenhuma contemplando o tema investigado.

O gráfico 2 apresenta os dados para a Universidade Federal do Estado do Rio de Janeiro (UNIRIO):

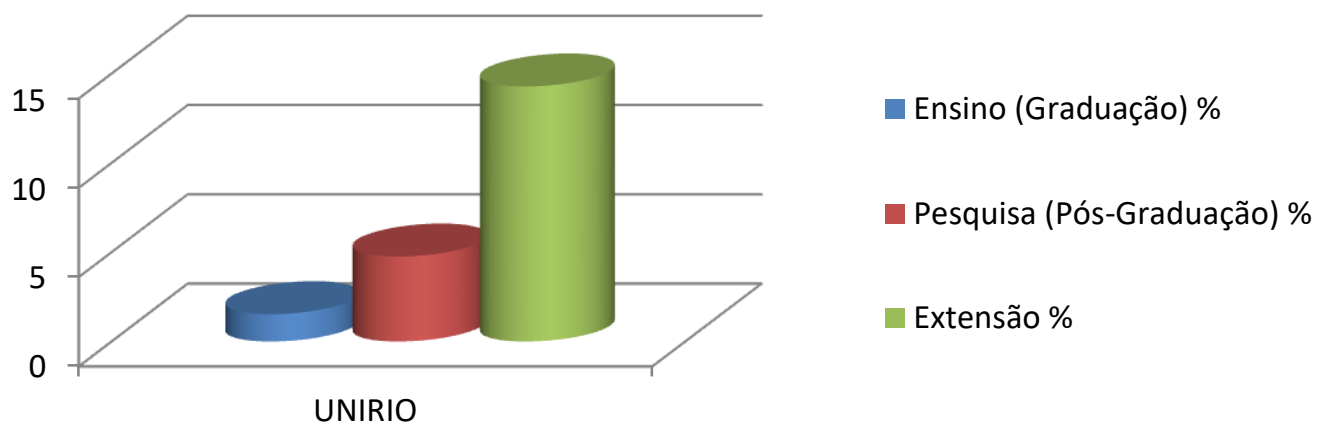

Gráfico 2. O Multiculturalismo no Ensino, Pesquisa e Extensão na Universidade Federal do Estado do Rio de Janeiro (UNIRIO)

Fonte: Dados obtidos através da análise dos documentos fornecidos pela instituição

\section{Universidade Federal do Estado Do Rio de Janeiro (UNIRIO)}

\footnotetext{
${ }^{8}$ Dados coletados no site https://inscricao.id.uff.br/consultaMatrizCurricular.uff, Acesso em: 02 jun. 2016.

${ }^{9}$ Dados coletados no site http://www.ci.uff.br/ppgci/, Acesso em: 02 jun. 2016.

${ }^{10}$ Dados coletados no site http://www.extensao.uff.br/, Acesso em: 02 jun. 2016.

\begin{tabular}{|c|c|c|c|c|c|}
\hline (C) RDBCI: Rev. Digit. Bibliotecon. Cienc. Inf. & Campinas, SP & v.16 & n. 2 & p.433-460 & maio/ago. 2018 \\
\hline
\end{tabular}


${ }^{11}$ Graduação (bacharelado e licenciatura) - 131 disciplinas ofertadas: 51 obrigatórias, 80 optativas.

1) Antropologia Cultural (disciplina optativa), graduação em bacharelado.

2) Biblioteconomia, Educação e Diversidade (disciplina optativa), graduação em licenciatura.

${ }^{12}$ Pós-graduação (Mestrado Profissional) - 21 disciplinas ofertadas: 2 obrigatórias, 19 optativas

1) Biblioteconomia, Multi/Interculturalismo e inclusão social (disciplina optativa)

${ }^{13}$ Extensão - Entre 7 projetos associados à área de biblioteconomia, 1 projeto contempla o tema investigado:

1)Programa "Etnoconhecimento para um etno(re)conhecimento: a importância da educação diferenciada e intercultural com qualidade social."

No Gráfico 2, identificamos a incidência de percentuais no Ensino (1,53\%), na Pesquisa (4,76\%) e na Extensão (14,28\%), referentes às disciplinas ofertadas e ações extensionistas que contemplam o tema investigado. De acordo com os Projetos Pedagógicos do Curso de graduação em Biblioteconomia (bacharelado e licenciatura) da UNIRIO, são ofertadas 131 disciplinas, sendo 51 obrigatórias e 80 optativas, analisadas as ementas de cada disciplina, concluiu-se que apenas 2 disciplinas contemplam o tema investigado, são elas: Antropologia Cultural, da graduação em bacharelado (disciplina optativa) e Biblioteconomia, Educação e Diversidade, da graduação em licenciatura (disciplina optativa), correspondendo à $1,53 \%$ do total das disciplinas ofertadas no curso. Na pós-graduação mestrado profissional em Biblioteconomia, são ofertadas 21 disciplinas, sendo 2 obrigatórias e 19 optativas, analisadas as suas ementas, concluiu-se que apenas 1 contempla o tema investigado, a disciplina Biblioteconomia, Multi/Interculturalismo e inclusão social (disciplina optativa), correspondendo 4,76\% do total das disciplinas ofertadas no curso. Analisando os programas, projetos e cursos de extensão associados à área de Biblioteconomia, foram encontrados 7 projetos, apenas um contemplando o tema investigado: "Etnoconhecimento para um etno(re)conhecimento: a importância da educação diferenciada e intercultural com qualidade social", correspondendo à $14,28 \%$ das ações de extensão.

A seguir, discutimos os dados para a Universidade Federal do Espírito Santo (UFES):

\footnotetext{
${ }^{11}$ Dados coletados no site http://www.unirio.br/unirio/cchs/eb/graducao, Acesso em: 07 jun. 2016

${ }^{12}$ Dados coletados no site http://www.unirio.br/ppgb, Acesso em: 07 jun. 2016.

${ }^{13}$ Dados coletados no site http://www2.unirio.br/unirio/proexc/dep.-de-extensao/acoes-de-extensaocadastradas/acoes-de-extensao-e-cultura-cadastradas-2016/view, Acesso em: 15 jan. 2014.

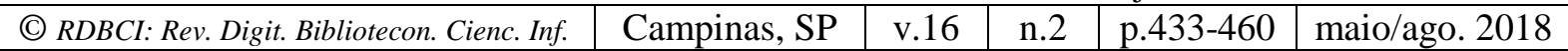




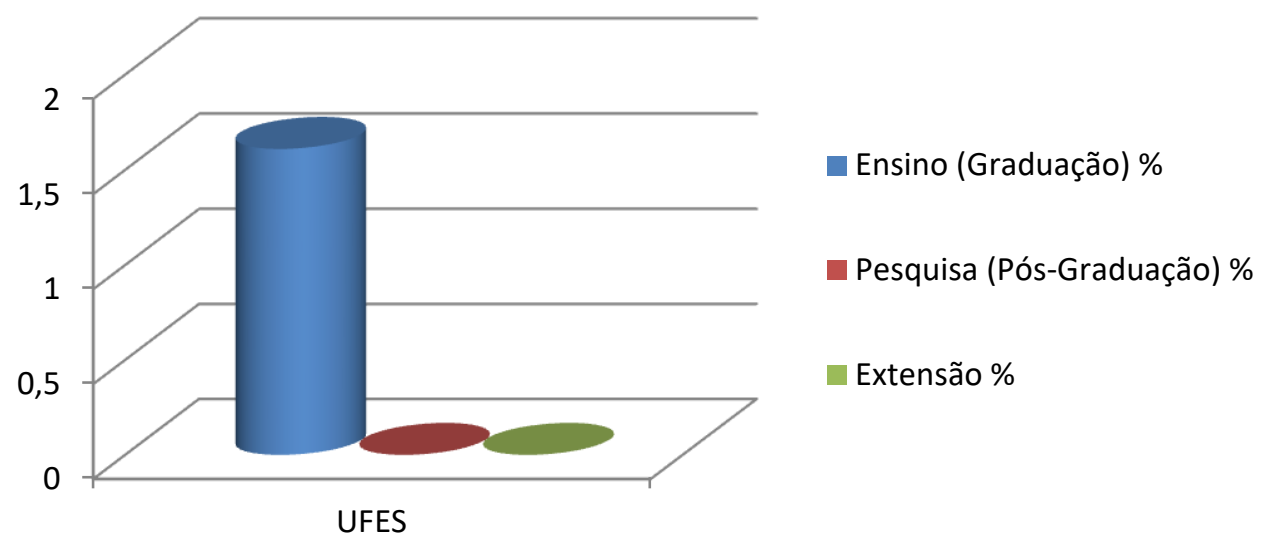

Gráfico 3. O Multiculturalismo no Ensino, Pesquisa e Extensão na Universidade Federal do Espirito Santo (UFES)

Fonte: Dados obtidos através da análise dos documentos fornecidos pela instituição

\section{Universidade Federal do Espirito Santo (UFES)}

${ }^{14}$ Graduação - 62 disciplinas ofertadas: 35 disciplinas obrigatórias, 27 disciplinas optativas.

1) Cultura Brasileira (disciplina obrigatória)

${ }^{15}$ Pós-graduação - Não ofertada na área.

${ }^{16}$ Extensão: 4 ações de extensão: 2 projetos, 2 eventos

No Gráfico 3, identificamos a incidência no Ensino $(1,61 \%)$ do total de disciplinas ofertadas no curso de graduação, que contemplam o tema investigado. Na Pesquisa (PósGraduação) não encontramos nenhum percentual, pois na instituição não é ofertada para a área. Na Extensão também não houve nenhum percentual. De acordo com o Projeto Pedagógico do Curso de graduação em Biblioteconomia da UFES, são ofertadas 62 disciplinas, sendo 35 obrigatórias e 27 optativas, analisadas as ementas de cada disciplina, concluiu-se que apenas 1 disciplina contempla o tema investigado, a disciplina Cultura Brasileira (disciplina obrigatória), correspondendo à 1,61\% do total das disciplinas ofertadas no curso. A pós-graduação em mestrado e doutorado não é ofertada na área. Analisando os programas, projetos e cursos de extensão associados à área, foram encontradas 4 ações, nenhuma contemplando o tema investigado.

No gráfico 4, apresentamos os dados para a Universidade Federal de Minas Gerais (UFMG):

\footnotetext{
${ }^{14}$ Dados coletados no site http://www.ufes.br/gradua\%C3\%A7\%C3\%A3o , Acesso em: 15 jun. 2016.

${ }^{15}$ Dados coletados no site http://www.ufes.br/p\%C3\%B3s-gradua\%C3\%A7\%C3\%A3o, Acesso em: 15 jun. 2016.

${ }^{16}$ Dados coletados no site http://proex.ufes.br/, Acesso em: 15 jun. 2016.

\begin{tabular}{|c|c|c|c|c|}
\hline (C) RDBCI: Rev. Digit. Bibliotecon. Cienc. Inf. & Campinas, SP & $\mathrm{v} .16$ & n.2 & maio/ago. 2018 \\
\hline
\end{tabular}
}




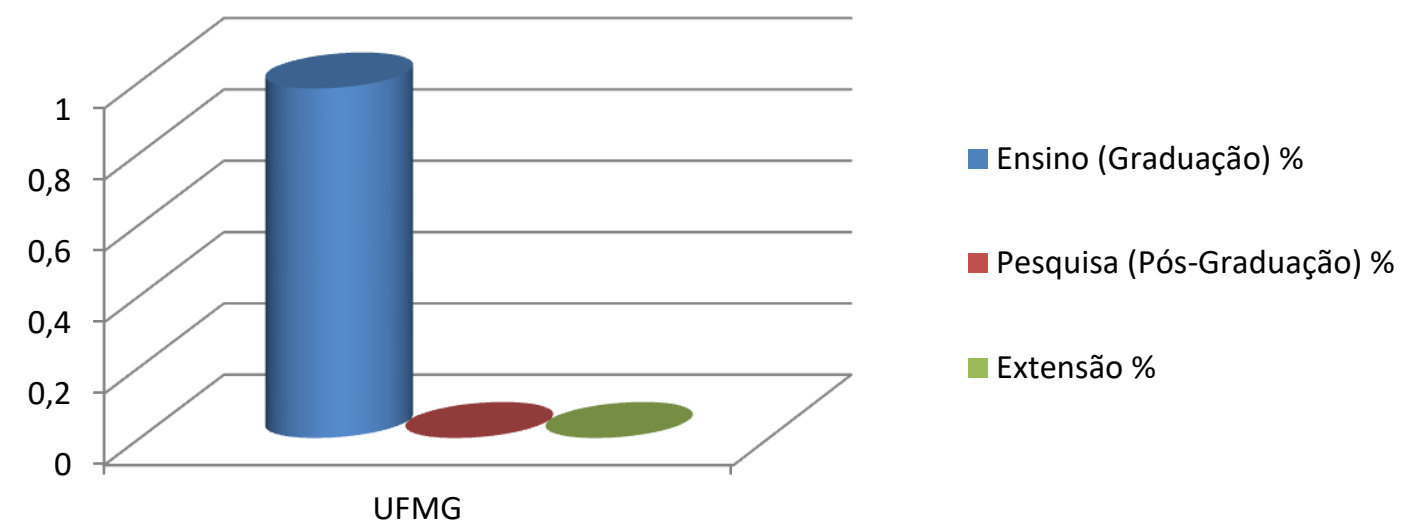

Gráfico 4. O Multiculturalismo no Ensino, Pesquisa e Extensão na Universidade Federal de Minas Gerais (UFMG)

Fonte: Dados obtidos através da análise dos documentos fornecidos pela instituição

\section{Universidade Federal de Minas Gerais (UFMG)}

${ }^{17}$ Graduação - 102 disciplinas ofertadas: 30 disciplinas obrigatórias, 72 disciplinas optativas. 1) Cultura e Informação (disciplina obrigatória)

${ }^{18}$ Pós-graduação (Mestrado e Doutorado) - 16 disciplinas ofertadas: 8 disciplinas obrigatórias, 8 disciplinas optativas.

${ }^{19}$ Extensão: 13 ações de extensão: 10 projetos, 3 programas

No Gráfico 4, encontramos a incidência no Ensino (0,98\%) do total das disciplinas ofertadas no curso de graduação. Para a Pesquisa e Extensão não encontramos nenhum percentual. De acordo com o Projeto Pedagógico do Curso de graduação em Biblioteconomia da UFMG, são ofertadas 102 disciplinas, sendo 30 obrigatórias e 72 optativas, analisadas as ementas de cada disciplina, concluiu-se que apenas 1 disciplina contempla o tema investigado, a disciplina Cultura e Informação (disciplina obrigatória), correspondendo 0,98 $\%$ do total das disciplinas ofertadas no curso. Na pós-graduação em mestrado e doutorado em Ciência da Informação, são ofertadas 16 disciplinas, sendo 8 obrigatórias e 8 optativas, analisadas as suas ementas, concluiu-se que nenhuma contempla o tema investigado. Analisando os programas, projetos e cursos de extensão associados à área, foram encontradas 13 ações, nenhuma contemplando o tema investigado.

A tabela, a seguir, apresenta os dados obtidos para o Ensino, a Pesquisa e a extensão, no tocante ao multiculturalismo nas Instituições Federais de Ensino Superior (IFES) da Região Nordeste.

\footnotetext{
${ }^{17}$ Dados coletados no site http://colgradbiblio.eci.ufmg.br/formularios/ementas-de-disciplinas, Acesso em: 17 jun. 2016.

${ }_{18}$ Dados coletados no site http://ppgci.eci.ufmg.br/cursos/mestrado, Acesso em: 17 jun. 2016.

${ }^{19}$ Dados coletados no site https://www2.ufmg.br/proex/, Acesso em: 17 jun. 2016.

\begin{tabular}{|c|c|c|c|c|c|}
\hline (C) RDBCI: Rev. Digit. Bibliotecon. Cienc. Inf. & Campinas, SP & v.16 & n.2 & p.433-460 & maio/ago. 2018 \\
\hline
\end{tabular}


Tabela 2. Percentual da temática do Multiculturalismo conforme o Ensino, a Pesquisa e a Extensão em cada IFES (Região Nordeste).

\begin{tabular}{|c|c|c|c|c|c|c|}
\hline \multirow{3}{*}{ Universidades } & \multicolumn{2}{|c|}{ Ensino } & \multicolumn{2}{|c|}{ Pesquisa } & \multicolumn{2}{|c|}{ Extensão } \\
\hline & \multicolumn{2}{|c|}{ (Graduação) } & \multicolumn{2}{|c|}{ (Pós-Graduação) } & \multicolumn{2}{|c|}{ (Ações) } \\
\hline & \multicolumn{2}{|c|}{ Freq. Abs. Freq. Rel.(\%) } & \multicolumn{2}{|c|}{ Freq. Abs. Freq. Rel.(\%) } & \multicolumn{2}{|c|}{ Freq. Abs. Freq. Rel.(\%) } \\
\hline UFAL & $0 / 53$ & 0 & $0 / 0$ & 0 & $0 / 1$ & 0 \\
\hline UFBA & $0 / 45$ & 0 & $0 / 48$ & 0 & $0 / 14$ & 0 \\
\hline UFC & $0 / 89$ & 0 & $0 / 26$ & 0 & $1 / 50$ & 2 \\
\hline UFCA & $1 / 64$ & 1,56 & $1 / 27$ & 3,70 & $0 / 21$ & 0 \\
\hline UFMA & $1 / 49$ & 2,04 & $0 / 0$ & 0 & $0 / 38$ & 0 \\
\hline UFPB & $0 / 58$ & 0 & $3 / 52$ & 5,77 & $0 / 8$ & 0 \\
\hline UFPE & $0 / 71$ & 0 & $0 / 15$ & 0 & $0 / 50$ & 0 \\
\hline UFRN & $1 / 62$ & 1,61 & $0 / 10$ & 0 & $0 / 5$ & 0 \\
\hline
\end{tabular}

Fonte: Dados obtidos através da análise dos documentos fornecidos por cada instituição.

De acordo com a Tabela 2, o tema ainda não faz parte do cenário acadêmico-cultural da Universidade Federal de Alagoas (UFAL), da Universidade Federal da Bahia (UFBA), e nem da Universidade Federal de Pernambuco (UFPE). Na Universidade Federal do Ceará (UFC) o tema aparece discretamente somente nas ações extensionistas (2\%), na Universidade Federal do Cariri (UFCA), o tema aparece na graduação (1,56\%) e na Pesquisa $(3,70 \%)$, já na Universidade Federal do Maranhão (UFMA) e na Universidade Federal do Rio Grande do Norte (UFRN), o tema aparece somente na graduação $(2,04 \%)$ e $(1,61 \%)$, respectivamente. $\mathrm{Na}$ Universidade Federal da Paraíba (UFPB), o tema aparece somente na Pesquisa $(5,77 \%)$.

O gráfico 5 apresenta os dados da Universidade Federal do Ceará (UFC): 


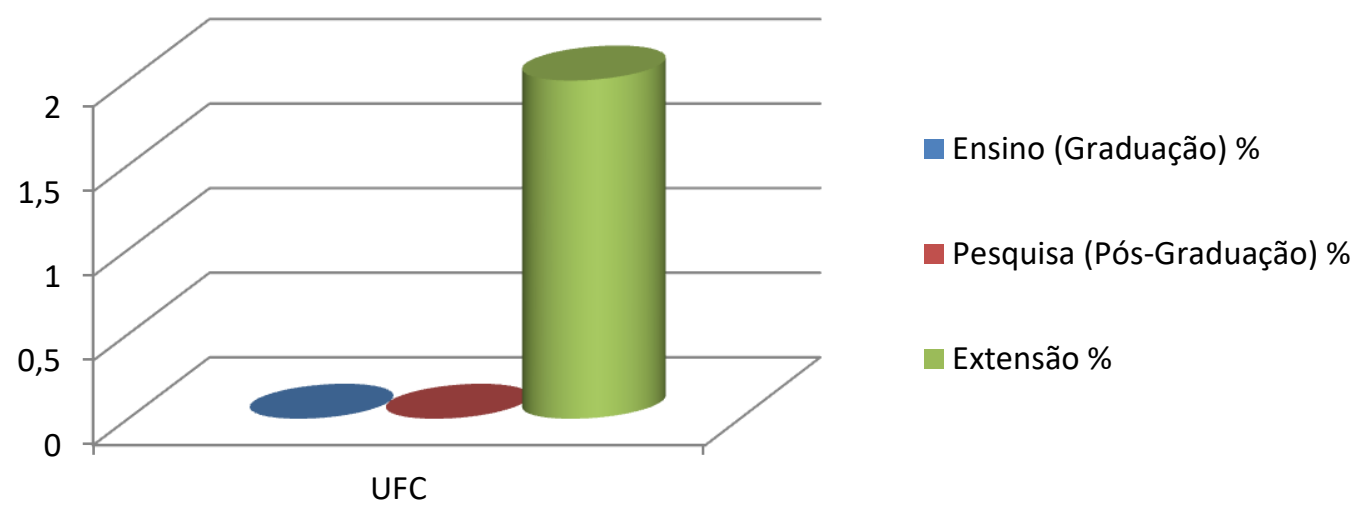

Gráfico 5. O Multiculturalismo no Ensino, Pesquisa e Extensão na Universidade Federal do Ceará (UFC)

Fonte: Dados obtidos através da análise dos documentos fornecidos pela instituição

\section{Universidade Federal do Ceará (UFC)}

${ }^{20}$ Graduação - 89 disciplinas ofertadas: 43 disciplinas obrigatórias, 46 disciplinas optativas ${ }^{21}$ Pós-graduação (Mestrado) - 26 disciplinas ofertadas: 3 disciplinas obrigatórias, 23 disciplinas optativas.

${ }^{22}$ Extensão: 50 ações de extensão: 1 projeto - Grupos sociais vulneráveis - questões de gênero, de etnia, de orientação sexual, de diversidade cultural, de credos religiosos, entre outros.

No Gráfico 5, não encontramos nenhuma incidência referente ao Ensino e Pesquisa. Na Extensão foi identificado um percentual de (2\%) referente ao total de ações extensionista para a área. De acordo com o Projeto Pedagógico do Curso de graduação em Biblioteconomia da UFC, são ofertadas 89 disciplinas, sendo 43 obrigatórias e 46 optativas, analisadas as ementas de cada disciplina, concluiu-se que nenhuma disciplina contempla o tema investigado, ou seja, $0 \%$ das disciplinas do curso de graduação em Biblioteconomia. Na pós-graduação em mestrado, são ofertadas 26 disciplinas, sendo 3 disciplinas obrigatórias e 23 disciplinas optativas. Analisadas as ementas das disciplinas ofertadas no mestrado profissional, concluise que nenhuma disciplina contempla o tema investigado. Analisando os programas, projetos e cursos de extensão associados à área, foram encontradas 50 ações, apenas 1 projeto de extensão contempla o tema investigado: "Grupos sociais vulneráveis - questões de gênero, de etnia, de orientação sexual, de diversidade cultural, de credos religiosos, entre outros", correspondendo $2 \%$ de todas as ações de extensão encontradas.

\footnotetext{
${ }^{20}$ Dados coletados no site http://www.ufc.br/ensino/cursos-de-graduacao/187-biblioteconomia-fortaleza, Acesso em: 30 jun. 2016.

${ }^{21}$ Dados coletados no site https://sucupira.capes.gov.br/sucupira/public/consultas/coleta/disciplina/listaDisciplina.jsf, Acesso em: 30 jun. 2016.

${ }^{22}$ Dados coletados no site http://www.ufc.br/extensao/programas-de-extensao, Acesso em: 30 jun. 2016.

\begin{tabular}{|c|c|c|c|c|c|}
\hline (C) RDBCI: Rev. Digit. Bibliotecon. Cienc. Inf. & Campinas, SP & v.16 & n. 2 & p.433-4 & maio/ago. 2018 \\
\hline
\end{tabular}
}


O gráfico 6, a seguir, disponibiliza os dados para a Universidade Federal do Cariri (UFCA)

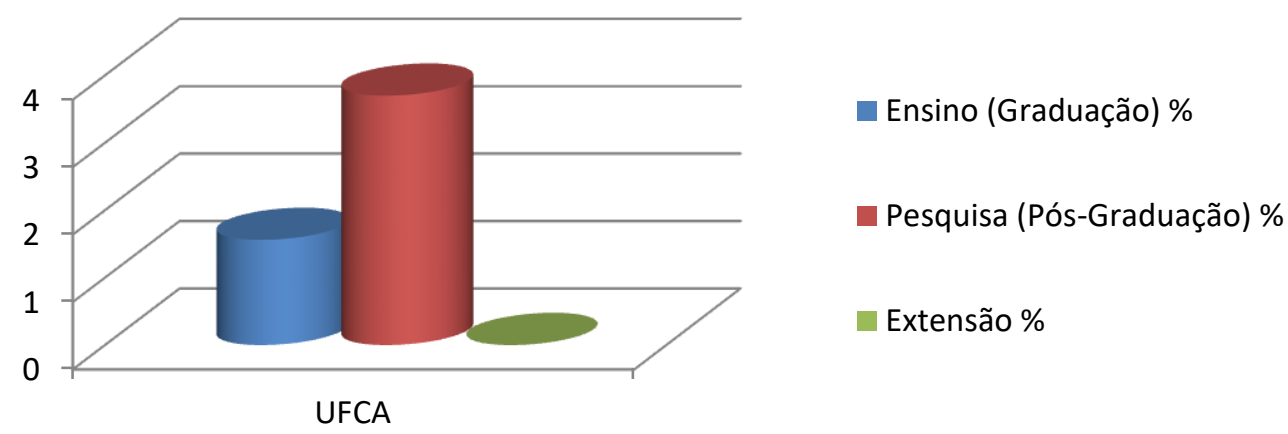

Gráfico 6. O Multiculturalismo no Ensino, Pesquisa e Extensão na Universidade Federal do Cariri (UFCA)

Fonte: Dados obtidos através da análise dos documentos fornecidos pela instituição

\section{Universidade Federal do Cariri (UFCA)}

${ }^{23}$ Graduação - 64 disciplinas ofertadas: 42 disciplinas obrigatórias, 22 disciplinas optativas

1) Relações Étnico-raciais e Africanidades (disciplina optativa)

${ }^{24}$ Pós-graduação (Mestrado Profissional) - 27 disciplinas ofertadas: 4 disciplinas obrigatórias, 23 disciplinas optativas.

1) Informação, Cultura Popular e Regional (disciplina optativa)

${ }^{25}$ Extensão: 21 ações de extensão.

No Gráfico 6, encontramos a incidência no Ensino (1,56\%) do total das disciplinas ofertadas no curso de graduação. Encontramos também a incidência na Pesquisa $(3,70 \%)$ do total de disciplinas ofertadas no Mestrado Profissional, e na Extensão não encontramos nenhum percentual. De acordo com o Projeto Pedagógico do Curso de graduação em Biblioteconomia da UFCA, são ofertadas 64 disciplinas, sendo 42 obrigatórias e 22 optativas, analisadas as ementas de cada disciplina, concluiu-se que apenas 1 disciplina contempla o tema investigado, a disciplina Relações Étnico-raciais e Africanidades (disciplina optativa), correspondendo à $1,56 \%$ do total das disciplinas ofertadas no curso. Na pós-graduação mestrado profissional em Biblioteconomia, são ofertadas 27 disciplinas, sendo 4 obrigatórias e 23 optativas, analisadas as suas ementas, concluiu-se que apenas 1 contempla o tema investigado, a disciplina Informação, cultura popular e regional (disciplina optativa), correspondendo à $3,70 \%$ do total das disciplinas ofertadas no curso. Analisando os programas, projetos e cursos de extensão associados à área, foram encontradas 21 ações,

\footnotetext{
${ }^{23}$ Dados coletados no site https://si3.ufc.br/sigaa/public/curso/curriculo.jsf?lc=pt BR\&id=657490, Acesso em: 12 dez. 2016.

${ }^{24}$ Dados coletados no site http://ppgb.ufca.edu.br/disciplinas-mpb, Acesso em: 12 dez. 2016.

${ }^{25}$ Dados coletados no site https://www.ufca.edu.br/portal/extensao/acoes-de-extensao-proex, Acesso em: 12 dez. 2016.
} 
nenhuma contemplando o tema investigado.

Disponibilizamos, no gráfico 7, os dados para a Universidade Federal do Maranhão (UFMA):

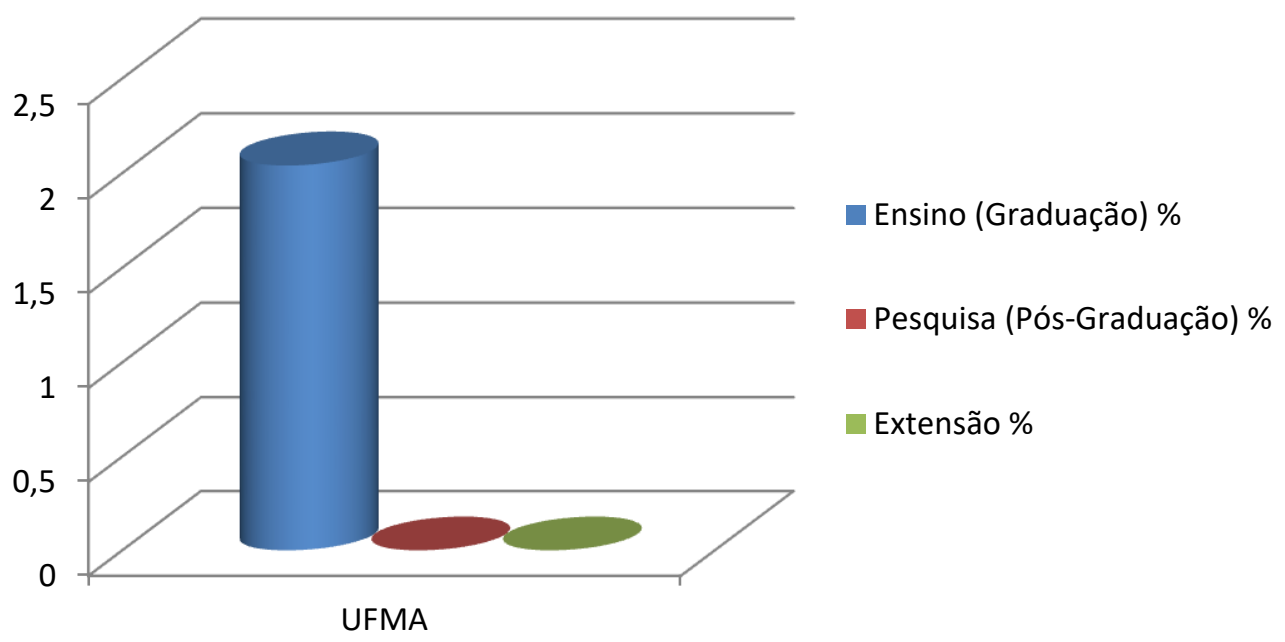

Gráfico 7. O Multiculturalismo no Ensino, Pesquisa e Extensão na Universidade Federal do Maranhão (UFMA)

Fonte: Dados obtidos através da análise dos documentos fornecidos pela instituição

\section{Universidade Federal do Maranhão (UFMA)}

${ }^{26}$ Graduação - 49 disciplinas ofertadas: 43 disciplinas obrigatórias, 6 disciplinas optativas

1) Estudo de Usuários e Pluriculturalismo (disciplina obrigatória)

${ }^{27}$ Pós-graduação - Não ofertada na área.

${ }^{28}$ Extensão: 38 ações de extensão.

No Gráfico 7, encontramos a incidência no Ensino (2,04\%) do total das disciplinas ofertadas no curso de graduação. Para a Pesquisa (Pós-Graduação), que não é ofertada na área pela instituição, e Extensão não encontramos nenhum percentual. Conforme o Projeto Pedagógico do Curso de graduação em Biblioteconomia da UFMA, que sofreu 3 modificações na sua matriz curricular nos anos de 1996, 1998 e 2007, são ofertadas 49 disciplinas, sendo 43 obrigatórias e 6 optativas, analisadas as ementas de cada disciplina, concluiu-se que apenas 1 disciplina contempla o tema investigado, a disciplina Estudo de Usuários e Pluriculturalismo (disciplina obrigatória), correspondendo à 2,04\% do total das disciplinas ofertadas no curso. A pós-graduação em mestrado e doutorado não é ofertada na área. Analisando os programas, projetos e cursos de extensão associados à área, foram

\footnotetext{
${ }^{26}$ Dados coletados no site https://sigaa.ufma.br/sigaa/public/curso/ppp.jsf?lc=pt_BR\&id=85812, Acesso em: 02 jul. 2016.

${ }^{27}$ Dados coletados no site https://sigaa.ufma.br/sigaa/public/programa/lista.jsf, Acesso em: 02 jul. 2016.

${ }^{28}$ Dados coletados no site https://sigaa.ufma.br/sigaa/public/extensao/consulta_extensao.jsf?aba=p-extensao,
} Acesso em: 02 jul. 2016. 
encontradas 38 ações, nenhuma contemplando o tema investigado.

O gráfico 8 apresenta os dados para a Universidade Federal da Paraíba (UFPB):

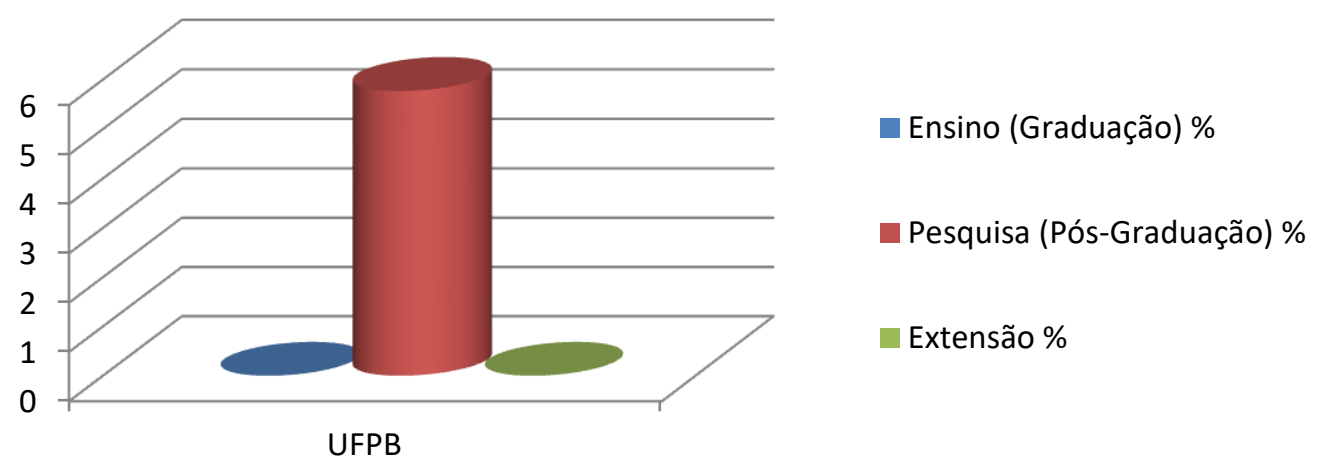

Gráfico 8. O Multiculturalismo no Ensino, Pesquisa e Extensão na Universidade Federal da Paraíba (UFPB)

Fonte: Dados obtidos através da análise dos documentos fornecidos pela instituição

\section{Universidade Federal da Paraíba (UFPB)}

${ }^{29}$ Graduação - 58 disciplinas ofertadas: 28 disciplinas obrigatórias, 30 disciplinas optativas.

${ }^{30}$ Pós-graduação (Mestrado e Doutorado) - 52 disciplinas ofertadas: 9 disciplinas obrigatórias, 43 disciplinas optativas.

1) Informação e Cultura (disciplina optativa comum aos dois cursos)

2) Informação e Inclusão Social (disciplina optativa comum aos dois cursos)

3) Informação e Patrimônio (disciplina optativa comum aos dois cursos)

${ }^{31}$ Extensão: 8 Programas.

No Gráfico 8, não encontramos nenhum percentual referente ao Ensino e Extensão. Na Pesquisa encontramos a incidência de $(5,77 \%)$ do total de disciplinas ofertadas pelo curso de Pós-graduação em mestrado e doutorado. De acordo com o Projeto Pedagógico do Curso de graduação em Biblioteconomia da UFPB, que iniciou em 1992, foi ampliado em 2004 e sofreu uma restruturação em 2008, são ofertadas 58 disciplinas, sendo 28 obrigatórias e 30 optativas, analisadas as ementas de cada disciplina, concluiu-se que nenhuma disciplina contempla o tema investigado, ou seja, $0 \%$ das disciplinas do curso de graduação em Biblioteconomia. Na pós-graduação em mestrado e doutorado, são ofertadas 52 disciplinas, sendo 9 disciplinas obrigatórias e 43 disciplinas optativas. Analisadas as ementas das disciplinas ofertadas no mestrado e doutorado, foram encontradas 3 disciplinas optativas comuns aos dois cursos, que contemplam a temática, são elas: Informação e Cultura,

\footnotetext{
${ }^{29}$ Dados coletados no site https://sigaa.ufpb.br/sigaa/public/departamento/componentes.jsf?id=1331, Acesso em: 05 jul. 2016.

${ }^{30}$ Dados coletados no site http://www.ccsa.ufpb.br/ppgci, Acesso em: 05 jul. 2016.

${ }^{31}$ Dados coletados no site http://www.prac.ufpb.br/, Acesso em: 05 jul. 2016.
}

\begin{tabular}{|c|c|c|c|c|}
\hline (C) RDBCI: Rev. Digit. Biblio & Campinas, SP & v.16 & $n$ & maio/ago. 2018 \\
\hline
\end{tabular}


Informação e Inclusão social, e Informação e Patrimônio, correspondendo à 5,77\% do total de disciplinas ofertadas. Analisando os programas, projetos e cursos de extensão associados à área, foram encontradas 8 ações, nenhuma contemplando o tema.

O gráfico 9, apresenta os dados para a Universidade Federal do Rio Grande do Norte (UFRN):

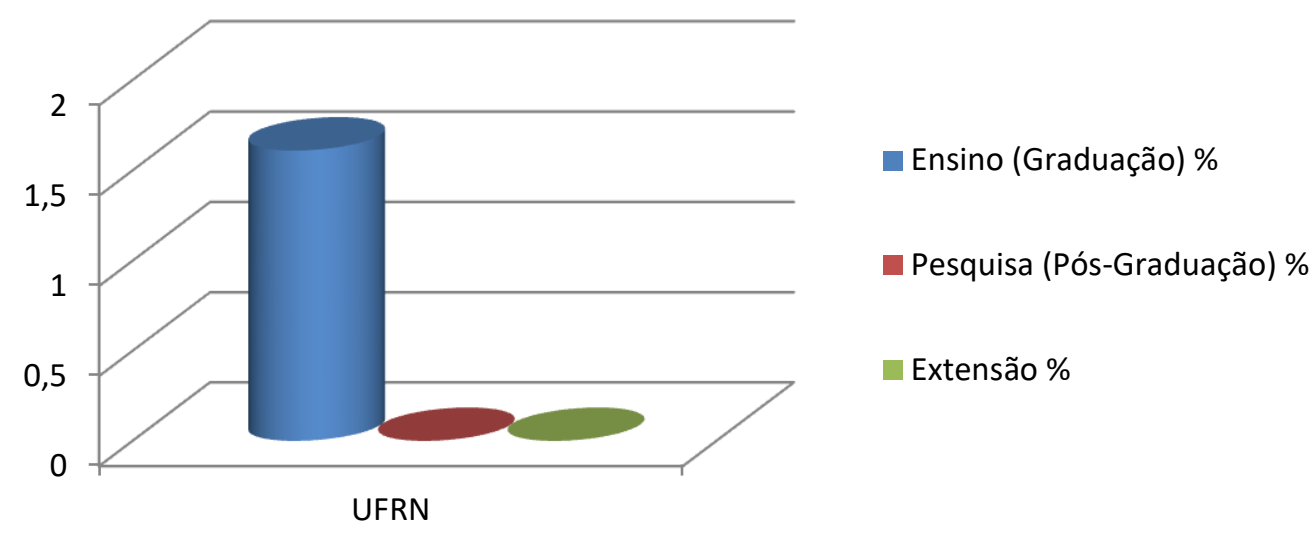

Gráfico 9. O Multiculturalismo no Ensino, Pesquisa e Extensão na Universidade Federal do Rio Grande do Norte (UFRN)

Fonte: Dados obtidos através da análise dos documentos fornecidos pela instituição

\section{Universidade Federal do Rio Grande do Norte (UFRN)}

${ }^{32}$ Graduação - 62 disciplinas ofertadas: 48 disciplinas obrigatórias, 14 disciplinas optativas

1) Cultura Brasileira (disciplina obrigatória)

${ }^{33}$ Pós-graduação (Mestrado Profissional) - 10 disciplinas ofertadas: 2 disciplinas obrigatórias, 8 disciplinas optativas.

${ }^{34}$ Extensão: 5 ações

No Gráfico 9, encontramos a incidência no Ensino (1,61\%) referente ao total das disciplinas ofertadas no curso de graduação. Na Pesquisa (Pós-graduação) e Extensão não foi encontrado nenhum percentual. De acordo com o Projeto Pedagógico do Curso de graduação em Biblioteconomia da UFRN, são ofertadas 62 disciplinas, sendo 48 obrigatórias e 14 optativas, analisadas as ementas de cada disciplina, concluiu-se que apenas 1 disciplina contempla o tema investigado, a disciplina Cultura Brasileira (disciplina obrigatória), correspondendo à $1,61 \%$ do total das disciplinas ofertadas no curso. A pós-graduação em mestrado profissional, são ofertadas 10 disciplinas, sendo 2 obrigatórias e 8 optativas.

\footnotetext{
${ }^{32}$ O curso de graduação em Biblioteconomia teve seu inicio no primeiro semestre de 1997 e sua matriz curricular foi restruturada por duas vezes, em 2008 e 2011. Dados coletados no site https://sigaa.ufrn.br/sigaa/public/curso/curriculo.jsf, Acesso em: 11 jul. 2016.

${ }^{33}$ Dados coletados no site https://sigaa.ufrn.br/sigaa/public/curso/lista.jsf?nivel=S\&aba=p-stricto, Acesso em: 06 fev. 2018.

${ }^{34}$ Dados coletados no site https://sistemas.ufrn.br/portal/PT/extensao/, Acesso em: 11 jul. 2016.
}

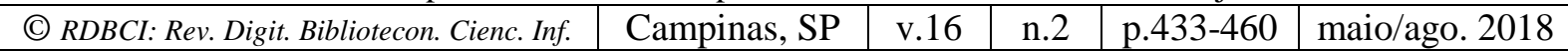


Analisadas as ementas das disciplinas ofertadas no mestrado profissional, conclui-se que nenhuma disciplina contempla o tema investigado. Analisando os programas, projetos e cursos de extensão associados à área, foram encontradas 5 ações, nenhuma contemplando a temática.

Analisando os dados da nossa investigação, considerando as duas Regiões pesquisadas, Sudeste e Nordeste, dentre as quatorze (14) universidades federais pesquisadas que oferecem o curso de Biblioteconomia e Ciência da Informação, seis (6) estão localizadas na Região Sudeste e oito (8) estão localizadas na Região Nordeste. Na Região Sudeste, três (3) universidades tratam da temática Multiculturalismo somente no Ensino (Graduação) e apenas uma (1) universidade trata do tema no Ensino (Graduação), na Pesquisa (Pós-Graduação) e na Extensão, ou seja, quatro (4) das seis (6) universidades da região anteriormente citada, tratam da temática em seus currículos e agendas, o que corresponde à $(66,66 \%)$ das universidades pesquisadas. Na Região Nordeste, duas (2) universidades tratam o tema somente no Ensino (Graduação), uma (1) universidade somente na Extensão, uma (1) somente na Pesquisa (Pós-graduação) e apenas uma (1) trata do tema no Ensino (Graduação) e na Pesquisa (Pós-graduação), ou seja, cinco (5) das oito (8) universidades da região anteriormente citada, tratam da temática em seus currículos e agendas, o que corresponde à $(62,8 \%)$ das universidades pesquisadas.

Desta forma, fazendo um comparativo entre as regiões Sudeste e Nordeste, temos como resultado, que na região Sudeste mais da metade das universidades pesquisadas, abordam a temática em seus currículos e agenda, enquanto que na Região Nordeste a incidência é um pouco menor. Concluímos, portanto, que apenas nove (9) das quatorze (14) universidades pesquisadas, abordam em seu currículo e agenda a temática investigada, o que corresponde à $(64,28 \%)$ das universidades federais das duas regiões citadas acima.

Embora os dados analisados apontem para a direção mencionada, reconhecemos que a oferta de disciplinas prevista na matriz curricular pode oscilar de um semestre para outro, e nesse caso, as disciplinas com a temática multiculturalismo são consideradas conforme exposto na matriz curricular de cada curso nas instituições investigadas.

Fazendo uma análise dos resultados dos dados apontados pela nossa pesquisa, considerando a baixa incidência de disciplinas com a temática Multiculturalismo e Diversidade Cultural na formação inicial e continuada do bibliotecário e do cientista da Informação, assim como também nas ações extensionistas existentes nas Instituições investigadas nas Regiões Sudeste e Nordeste, podemos compará-los com os resultados encontrados na pesquisa realizada em 2011 na Dissertação de Mestrado ${ }^{35}$ de Miriam Mattos, na qual ela descreve:

\footnotetext{
${ }^{35}$ MATTOS, Miriam. Multiculturalismo em Ciência da Informação: Percepções e Ações dos Profissionais da Informação em Bibliotecas Escolares. Dissertação de Mestrado apresentada ao Programa de Pós-Graduação em \begin{tabular}{l|l|l|l|l|l} 
(C) RDBCI: Rev. Digit. Bibliotecon. Cienc. Inf. & Campinas, SP & v.16 & n.2 & p.433-460 & maio/ago. 2018 \\
\hline
\end{tabular} 
A pesquisa revelou que, quanto à formação acadêmica, foi amplamente majoritária a manifestação dos profissionais pesquisados de que não tiveram, em suas graduações e pós-graduações, abordagens sobre conteúdos como multiculturalismo, diversidade cultural, respeito às diferenças, acessibilidade, gênero ou afins. (MATTOS, 2011, p.110)

A tendência apontada por Miriam Mattos acerca dos resultados de sua pesquisa, restrita aos profissionais bibliotecários atuantes em bibliotecas escolares da cidade de Florianópolis/SC e graduados pela Universidade Federal de Santa Catarina (UFSC) e pela Universidade do Estado de Santa Catarina (UDESC), é confirmada pelo cenário encontrado em nossa pesquisa nas IFES das Regiões Sudeste e Nordeste.

Considerando que os bibliotecários também atuam em ambientes educativos, a concepção da "Educação Intercultural" se faz necessária onde existe o relacionamento de indivíduos de culturas diferentes, nesse sentido Fleuri (2000) afirma que:

[...] educação intercultural propõe construir a relação recíproca entre eles. Uma relação que se dá, não abstratamente, mas entre pessoas concretas. Entre sujeitos que decidem construir contextos e processos de aproximação, de conhecimento recíproco e de interação. Relações estas que produzem mudanças em cada indivíduo, favorecendo a consciência de si e reforçando a própria identidade. (FLEURI, 2000, p.79)

Os nossos resultados muito se assemelham aos resultados da pesquisa de Mattos (2011) no sentido de apontar para uma direção comum, qual seja, a de que o tema multiculturalismo e diversidade cultural é muito pouco recorrente na formação inicial e continuada do bibliotecário. Considerando esta lacuna no currículo, Mattos faz alguns questionamentos:

[...] em que medida o profissional bibliotecário atuante [...] está qualificado para lidar com o novo contexto educacional, onde temáticas como multiculturalismo, acessibilidade e diversidade implicam no reconhecimento da diversidade cultural e no respeito ao direito à diferença? Esses profissionais conhecem e contribuem para a aplicação das 21 leis que normatizam essas temáticas? Qual a percepção desses profissionais sobre multiculturalismo? A formação inicial e continuada dos bibliotecários contribui para a plena adequação dos mesmos à implementação de uma educação multicultural? (MATTOS, 2011, p.20).

A pesquisa que deu origem à publicação do trabalho da Professora Doutora Patrícia Vargas, apresentado no XV ENANCIB no ano de 2014, também apresenta dados que são confirmados em nossa pesquisa, no que tange ao conhecimento por parte dos alunos do curso de Mestrado Profissional em Biblioteconomia, relacionado às discussões associadas à Diversidade Cultural:

De acordo com os dados, metade (50\%) admitiu que não tinha conhecimento sobre

Ciência da Informação, Faculdade de Filosofia e Ciências, Universidade Estadual Paulista, Marília, São Paulo: 2011.

V.16

n.2

p.433-460 1 maio/ago. 2018


as discussões relacionadas à diversidade cultural no universo biblioteconômico e $25 \%$ admitiram ter conhecimento mediano sobre o assunto. A minoria assinalou que conhece muito bem (8\%), conhece consideravelmente $(8 \%)$ e conhece pouco $(8 \%)$. (ALENCAR, 2014, p. 9)

Diante do cenário confirmado pelas pesquisas mencionadas, mister se faz a discussão da pauta sobre o Multiculturalismo em uma sociedade plural já que, conforme Boaventura Santos (2003):

As versões emancipatórias do multiculturalismo baseiam-se no reconhecimento da diferença e do direito à diferença e da coexistência ou construção de uma vida em comum além de diferenças de vários tipos. (SANTOS, 2003, p. 33)

Na mesma direção, Hall (2003) menciona a necessidade de "estratégias e políticas usadas para governar ou administrar problemas de diversidade e multiplicidade em sociedades multiculturais" (HALL, 2003, p.52)

Nossa pesquisa reconhece tal demanda da Sociedade Multicultural e acena para a relevância de se discutir o Multiculturalismo nos cursos de formação inicial da área da Biblioteconomia e da Ciência da Informação. A seguir, tecemos nossas considerações finais.

\section{CONSIDERAÇões FINAIS}

Esta pesquisa traz evidências de que, tanto na formação inicial quanto na formação continuada do bibliotecário e do cientista da informação, existe uma lacuna, nos cursos das universidades federais no Sudeste e Nordeste brasileiro referente a abordagens relacionadas ao Multiculturalismo quanto ao ensino, à pesquisa e à extensão.

Ao que tudo indica, o cenário encontrado pode se estender a outras universidades federais das demais regiões do Brasil que oferecem o curso de graduação e pós-graduação em Biblioteconomia e Ciência da Informação já que há um "silenciamento" da temática nos trabalhos da revisão da literatura, conforme nossa pesquisa aponta.

Embora esta pesquisa não esgote a discussão aqui proposta, sua contribuição é abrir espaço para novas pesquisas sobre o Multiculturalismo, com vistas a discutir o posicionamento silencioso das universidades no tocante à temática na formação inicial e continuada nos cursos de Biblioteconomia e Ciência da Informação.

\section{REFERÊNCIAS}

ALENCAR, P. V. . Mediação da Informação no fazer do bibliotecário no âmbito do Interculturalismo. In: ENANCIB 2014 XV Encontro Nacional de Pesquisa em Ciência da Informação/ Além das nuvens: Expandindo as Fronteiras da Ciência da Informação, 2014, Belo Horizonte. Anais eletrônicos... 2014. Disponível em:

<http://enancib2014.eci.ufmg.br/documentos/anais/anais-gt6>. Acesso em: 05 ago 2015. 
CONSELHO REGIONAL DE BIBLIOTECONOMIA. Carreira CRB - 6. Disponivel em: <http://www.crb6.org.br/carreira.php>. Acesso em 20 jul. 2014.

DUARTE, Teresa et al. A possibilidade da investigação a 3: reflexões sobre triangulação (metodológica). CIES e-working, Portugal, v. 60, 2009. Disponível em: <http://cies.iscteiul.pt/destaques/documents/CIES-WP60_Duarte_001.pdf>. Acesso em: 20 nov. 2016.

FLEURI, Reinaldo Matias. Multiculturalismo e interculturalismo nos processos educacionais. In.: CANDAU, Vera Maria et all. Ensinar e aprender: sujeitos, saberes e pesquisa. Rio de Janeiro: DP\&A, 2000, p. $67-81$.

GIL, Antonio Carlos. Como elaborar projetos de pesquisa. 4 ed. São Paulo: Atlas, 2002.

HALL, Stuart. Da Diáspora: Identidades e mediações culturais. Trad.: Adelaide la Guardiã Resende et al. Belo Horizonte: Editora UFMG. 2003.

INTERNATIONAL FEDERATION OF LIBRARY ASSOCIATIONS AND

INSTITUTIONS . Manifesto por la biblioteca multicultural, 2008. Disponível em: $<$ http://www.ifla.org/files/assets/library-services-to-multiculturalpopulations/publications/multicultural_library_manifesto-es.pdf >. Acesso em: 10 ago.2016.

MATTOS, Miriam; MURGUIA, Eduardo. Multiculturalismo em Ciência da Informação: percepções e ações dos profissionais da informação em bibliotecas escolares de Florianópolis. In: ENCONTRO NACIONAL DE PESQUISA EM CIÊNCIA DA INFORMAÇÃO - ENANCIB, 10. Anais...João Pessoa: UFPB, 2009

MATTOS, Miriam. Multiculturalismo em Ciência da Informação: percepções e ações dos profissionais da informação em bibliotecas escolares. Dissertação de Mestrado apresentada ao Programa de Pós-Graduação em Ciência da Informação, Faculdade de Filosofia e Ciências, Universidade Estadual Paulista, Marília, São Paulo: 2011. Disponível em: $<$ http://www.marilia.unesp.br/Home/Posgraduacao/CienciadaInformacao/Dissertacoes/mattos_mccm_me_mar.pdf >. Acesso em: 19 set. 2013.

MINAYO, M.C.S. O desafio do conhecimento científico: pesquisa qualitativa em saúde. 2. ed. São Paulo: Hucitec - Abrasco,1994.

RICHARDSON, R. J. Pesquisa Social: métodos e técnicas. 3 ed. São Paulo: Atlas, 1999.

SANTOS, Boaventura de Sousa. NUNES, João Arriscado. Introdução: para ampliar o cânone do reconhecimento, da diferença e da igualdade. In: SANTOS, Boaventura de Sousa (org.). Reconhecer para libertar: os caminhos do cosmopolitismo multicultural. Rio de Janeiro: Civilização Brasileira, 2003.

UNESCO. Declaração universal sobre a diversidade cultural. 2002. Disponível em: <http://unesdoc.unesco.org/images/0012/001271/127160por.pdf>. Acesso em: 19 ago. 2015

UNIVERSIDADE FEDERAL DA BAHIA. Graduação. Disponível em: <https://blog.ufba.br/ici/ensino/biblioteconomia/>. Acesso em: 25 jun. 2016. 
UNIVERSIDADE FEDERAL DA BAHIA. Pós-graduação. Disponível em: <https://ppgci.ufba.br/disciplinas >. Acesso em: 25 jun. 2016.

UNIVERSIDADE FEDERAL DA BAHIA. Extensão. Disponível em: <https://proext.ufba.br/>. Acesso em: 25 jun. 2016.

UNIVERSIDADE FEDERAL DA PARAÍBA. Graduação. Disponível em: 〈https://sigaa.ufpb.br/sigaa/public/departamento/componentes.jsf?id=1331>. Acesso em: 05 jul. 2016.

UNIVERSIDADE FEDERAL DA PARAÍBA. Pós-graduação. Disponível em: <http://www.ccsa.ufpb.br/ppgci >. Acesso em: 05 jul. 2016.

UNIVERSIDADE FEDERAL DA PARAÍBA. Extensão. Disponível em: <http://www.prac.ufpb.br/,>. Acesso em: 05 jul. 2016

UNIVERSIDADE FEDERAL DE ALAGOAS. Graduação. Disponível em: $<$ http://www.ufal.edu.br/estudante/graduacao/projetos-pedagogicos/campus-maceio/ppcbiblioteconomia.pdf/view>. Acesso em: 21 jun. 2016.

UNIVERSIDADE FEDERAL DE ALAGOAS. Pós-graduação. Disponível em: $\langle$ http://www.ufal.edu.br/estudante/pos-graduacao-e-pesquisa/mestrado $>$. Acesso em: 21 jun. 2016.

UNIVERSIDADE FEDERAL DE ALAGOAS. Extensão. Disponível em: <http://www.ufal.edu.br/estudante/extensao/documentos, $>$. Acesso em: 22 jun. 2016.

UNIVERSIDADE FEDERAL DE MINAS GERAIS. Graduação. Disponível em: $\langle$ http://colgradbiblio.eci.ufmg.br/formularios/ementas-de-disciplinas $>$. Acesso em: 17 jun. 2016

UNIVERSIDADE FEDERAL DE MINAS GERAIS. Pós-Graduação. Disponível em: <http://ppgci.eci.ufmg.br/cursos/mestrado $>$. Acesso em: 17 jun. 2016.

UNIVERSIDADE FEDERAL DE MINAS GERAIS. Extensão. Disponível em: <https://www2.ufmg.br/proex/>. Acesso em: 17 jun. 2016.

UNIVERSIDADE FEDERAL DE PERNAMBUCO. Graduação. Disponível em: $<$ https://www.ufpe.br/proacad/images/cursos_ufpe/biblioteconomia_perfil_0406.pdf > Acesso em: 08 jul. 2016.

UNIVERSIDADE FEDERAL DE PERNAMBUCO. Pós-Graduação. Disponível em: $<$ https://www.ufpe.br/ppgci/index.php?option=com_content $\&$ view=article \&id=303\&Itemid= 233>. Acesso em: 08 jul. 2016.

UNIVERSIDADE FEDERAL DE PERNAMBUCO. Extensão. Disponível em: $<$ https://www.ufpe.br/proexc/index.php?option=com_content $\&$ view $=$ article $\& i d=2084 \% 3 \mathrm{Apr}$ ojetos-de-extensao-ufpe-registrados-em-2015\&catid=1\%3Aa-proext\&Itemid=108> . Acesso em: 08 jul. 2016.

\begin{tabular}{l|l|l|l|l|l}
\hline (C) RDBCI: Rev. Digit. Bibliotecon. Cienc. Inf. & Campinas, SP & v.16 & n.2 & p.433-460 & maio/ago. 2018 \\
\hline
\end{tabular}


UNIVERSIDADE FEDERAL DE SÃO CARLOS. Graduação. Disponível em: $<$ http://www.prograd.ufscar.br/cursos/cursos-oferecidos-1/biblioteconomia-e-ciencia-dainformacao/biblioteconomia-e-ciencia-da-informacao>. Acesso em: 10 jun. 2016.

UNIVERSIDADE FEDERAL DE SÃO CARLOS. Pós-graduação. Disponível em: $\langle$ http://www.ppgci.ufscar.br/>. Acesso em 10 jun. 2016

UNIVERSIDADE FEDERAL DE SÃO CARLOS. Extensão, Disponível em: <http://www.proex.ufscar.br/>. Acesso em 10 jun. 2016

UNIVERSIDADE FEDERAL DO CARIRI. Graduação. Disponível em: $<$ https://si3.ufc.br/sigaa/public/curso/curriculo.jsf?lc=pt_BR\&id=657490>. Acesso em: 12 dez. 2016.

UNIVERSIDADE FEDERAL DO CARIRI. Pós-graduação. Disponível em: <http://ppgb.ufca.edu.br/disciplinas-mpb/>. Acesso em: 12 dez. 2016.

UNIVERSIDADE FEDERAL DO CARIRI. Extensão. Disponível em: $<$ https://www.ufca.edu.br/portal/extensao/acoes-de-extensao-proex>. Acesso em: $12 \mathrm{dez}$. 2016.

UNIVERSIDADE FEDERAL DO CEARÁ. Graduação. Disponível em: <http://www.ufc.br/ensino/cursos-de-graduacao/187-biblioteconomia-fortaleza>. Acesso em: 30 jun. 2016.

UNIVERSIDADE FEDERAL DO CEARÁ. Pós-graduação. Disponível em: <https://sucupira.capes.gov.br/sucupira/public/consultas/coleta/disciplina/listaDisciplina.jsf>. Acesso em: 30 jun. 2016.

UNIVERSIDADE FEDERAL DO CEARÁ. Extensão. Disponível em: <http://www.ufc.br/extensao/programas-de-extensao>. Acesso em: 30 jun. 2016.

UNIVERSIDADE FEDERAL DO ESPIRITO SANTO. Graduação. Disponível em: <http://www.ufes.br/gradua\%C3\%A7\%C3\%A3o>. Acesso em 15 jun. 2015.

UNIVERSIDADE FEDERAL DO ESPIRITO SANTO. Pós-graduação. Disponível em: <http://www.ufes.br/p\%C3\%B3s-gradua\%C3\%A7\%C3\%A3o>. Acesso em 15 jun. 2015.

UNIVERSIDADE FEDERAL DO ESPIRITO SANTO. Extensão. Disponível em <http://proex.ufes.br/>. Acesso em: 15 jun. 2015.

UNIVERSIDADE FEDERAL DO ESTADO DO RIO DE JANEIRO. Graduação. Disponivel em: 〈http://www.unirio.br/unirio/cchs/eb/graducao >. Acesso em: 07 jun. 2016

UNIVERSIDADE FEDERAL DO ESTADO DO RIO DE JANEIRO. Pós -graduação. Disponível em: 〈http://www.unirio.br/unirio/cchs/eb/graducao >. Acesso em: 07 jun. 2016

UNIVERSIDADE FEDERAL DO ESTADO DO RIO DE JANEIRO. Extensão. Disponível em: <http://www2.unirio.br/unirio/proexc/dep.-de-extensao/acoes-de-extensaocadastradas/acoes-de-extensao-e-cultura-cadastradas-2016/view>. Acesso em: 15 jan. 2014

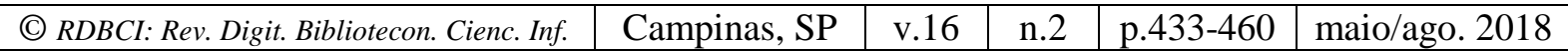


UNIVERSIDADE FEDERAL DO MARANHÃO. Graduação. Disponível em: $<$ https://sigaa.ufma.br/sigaa/public/curso/ppp.jsf?lc=pt_BR\&id=85812>. Acesso em: 02 jul. 2016.

UNIVERSIDADE FEDERAL DO MARANHÃO. Pós-graduação. Disponível em: 〈https://sigaa.ufma.br/sigaa/public/programa/lista.jsf>. Acesso em: 02 jul. 2016.

UNIVERSIDADE FEDERAL DO MARANHÃO. Extensão. Disponível em: $<$ https://sigaa.ufma.br/sigaa/public/extensao/consulta_extensao.jsf?aba=p-extensao $>$. Acesso em: 02 jul. 2016.

UNIVERSIDADE FEDERAL DO RIO DE JANEIRO. Graduação. Disponível em: $<$ https://www.siga.ufrj.br/sira/temas/zire/frameConsultas.jsp?mainPage=/repositoriocurriculo/E4BF91B2-92A4-F713-00FD-C0153E641DC7.html >. Acesso em: 10 jun. 2016.

UNIVERSIDADE FEDERAL DO RIO DE JANEIRO. Pós-graduação. Disponível em: <http://www.pr2.ufrj.br/pr2/listarStrictoMestreDoutor>. Acesso em: 10 jun. 2016.

UNIVERSIDADE FEDERAL DO RIO DE JANEIRO. Extensão. Disponível em: <http://www.pr5.ufrj.br/>. Acesso em: 10 jun. 2016.

UNIVERSIDADE FEDERAL DO RIO GRANDE DO NORTE. Graduação. Disponível em: <https://sigaa.ufrn.br/sigaa/public/curso/curriculo.jsf>. Acesso em: 11 jul. 2016.

UNIVERSIDADE FEDERAL DO RIO GRANDE DO NORTE. Pós-graduação. Disponível em: 〈https://sigaa.ufrn.br/sigaa/public/curso/lista.jsf?nivel=S\&aba=p-stricto>. Acesso em: 06 fev. 2018.

UNIVERSIDADE FEDERAL DO RIO GRANDE DO NORTE. Extensão. Disponível em: $<$ https://sistemas.ufrn.br/portal/PT/extensao/>. Acesso em: 11 jul. 2016.

UNIVERSIDADE FEDERAL FLUMINENSE. Graduação. Disponível em:

<https://inscricao.id.uff.br/consultaMatrizCurricular.uff>. Acesso em: 02 jun. 2016.

UNIVERSIDADE FEDERAL FLUMINENSE. Pós-Graduação. Disponível em: <http://www.ci.uff.br/ppgci/>. Acesso em: 02 jun. 2016.

UNIVERSIDADE FEDERAL FLUMINENSE. Extensão. Disponível em: <http://www.extensao.uff.br/>. Acesso em: 02 jun. 2016.
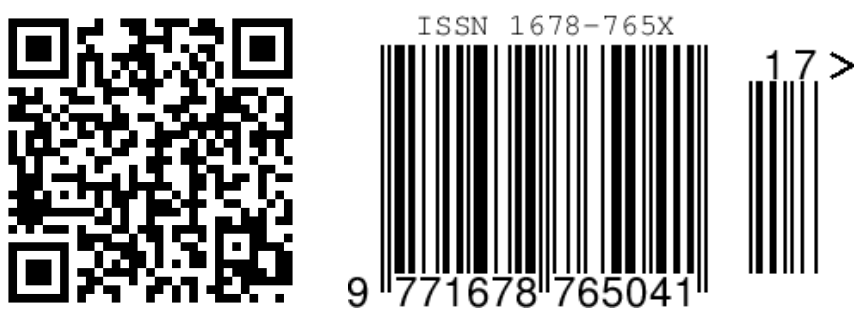